\title{
Passage rates of digesta from the rumen in wethers fed timothy and alfalfa hay at three different intake levels
}

\author{
T Onshita, T Kyuma, T Kondo \\ Tohoku Agricultural Experimental Station, Shimokuriyagawa, Morioka 020-01, Japan
}

Passage rate of digesta from the rumen is one of the most important factors that affects the extent and site of digestion and is closely related to feeding level. Ruminal passage rate may differ depending on forage species fed but there are few studies on such variation in passage rate. In the present work we compared passage rates of digesta in wethers fed timothy (Phleum pratense L.) and alfalfa (Medicago sativa $L$.) at three different intake levels (daily dry matter intake : 1, 2 and $2.5 \%$ of body weight).

Animal feeding trials were conducted using four wethers (average weight $62.3 \pm 2.3 \mathrm{~kg}$ ) per a plot. Wethers were once daily fed timothy or alfalfa hay during 7-day adaptation period and a 14-day sampling period. Apparent digestibilities were measured by total fecal collection method. Passage rates were estimated from fecal excretion curves of Cobalt and Dysprosium dosed as the markers of fluid and particulate phases, respectively, on the basis of the two compartment model of Grovum and Williams (1973, Br J Nutr, 30, 313-329). The markers were prepared and dosed by the procedures outlined by Moore et al (1992, J Anim Sci, 70, 3528-3540) with a modification.

The timothy hay contained $16.2 \%$ crude protein (CP), $58.8 \%$ neutral detergent fiber (NDF) and $35.6 \%$ acid detergent fiber (ADF) and the alfalfa hay contained $16.2 \% \mathrm{CP}$, $44.1 \%$ NDF and $38.5 \%$ ADF. The apparent digestibilities of organic matter (OM), NDF and ADF were higher for timothy than for alfalfa and decreased with increasing dry matter intake (DMI). Ruminal particulate and fluid passage rates increased with increasing DMI. A significant difference was found in particulate passage rate between alfalfa and timothy ; when compared at similar DMI levels, alfalfa showed 1.5-1.7 times higher rate than timothy. In contrast, fluid passage rate did not differ between the two forages. For alfalfa, particulate passage rate was similar to fluid passage rate at each DMI level.

Results confirmed the strong effect of intake level on passage rates and also indicated a marked difference in particulate passage rate between alfalfa and timothy.

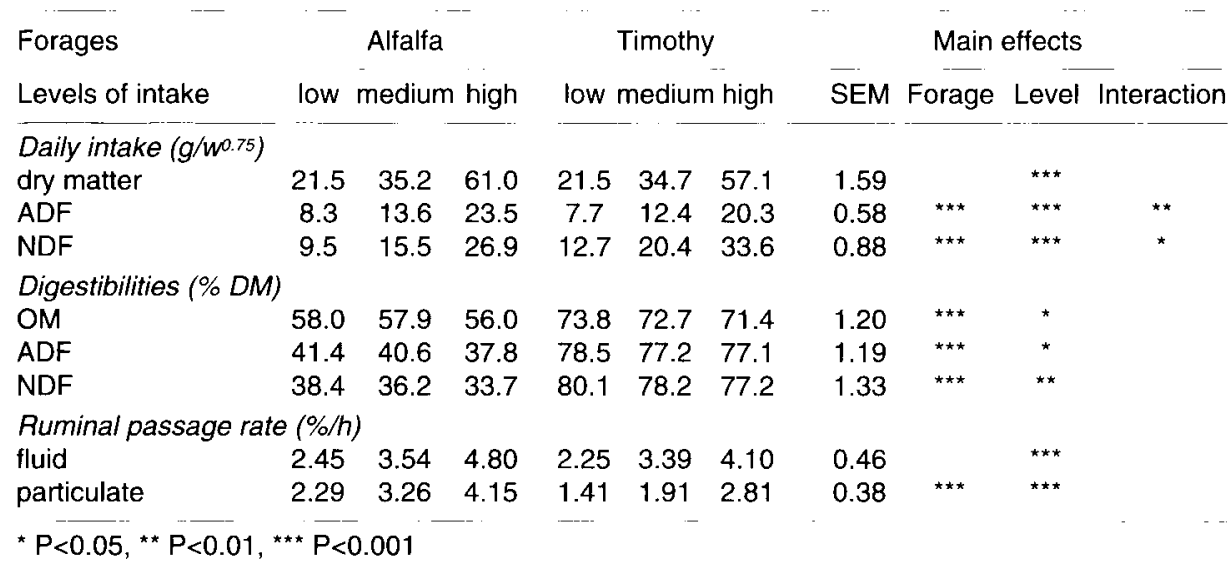

